\title{
Welcome to the 16th volume of Future Oncology
}

\author{
Rachel Jenkins*,1 \& Louis Gautier ${ }^{1}$ \\ ${ }^{1}$ Future Science Group, Unitec House, 2 Albert Place, London N3 1QB, UK \\ *Author for correspondence: r.jenkins@futuremedicine.com
}

First draft submitted: 12 November 2019; Accepted for publication: 15 November 2019; Published online: 3 December 2019

Keywords: cancer $\bullet$ clinical trial $\bullet$ genomics $\bullet$ immunotherapy $\bullet$ oncology $\bullet$ precision medicine $\bullet$ real-world evidence - research • social media $\bullet$ treatment sequencing

To all our readers, we are delighted to welcome you to the 16th volume of Future Oncology. The year 2019 was another exciting year for the journal, with the continued publication of timely, high quality and impactful manuscripts. Highlights of the last year include an issue increase to 36 issues per year, a special focus issue discussing optimal treatment sequences and an even stronger collaboration with our online knowledge hub, OncologyCentral [1,2].

We would also like to take this opportunity to thank all of our valued Editorial Board members, readers and contributors for their continued support. As we move into 2020, we look forward to aiding the journals' continued progression and development as well as considering the landscape of cancer research over the next decade.

\section{Content highlights of 2019}

At the time of writing (November 2019), our most read article was a short communication by Maximilian Hochmair (Otto Wagner Hospital, Vienna, Austria) and colleagues titled 'Sequential afatinib and osimertinib in patients with EGFR mutation-positive non-small-cell lung cancer: updated analysis of the observational GioTag study' [3]. This study provided an update on previous results from the original GioTag study published in Future Oncology in $2018[4]$.

Another of our most popular reads was a short communication titled 'Nintedanib plus docetaxel after progression on immune checkpoint inhibitor therapy: insights from VARGADO, a prospective study in patients with lung adenocarcinoma’ by Christian Groché (Evangelische Lungenklinik, Berlin, Germany) and colleagues [5]. The article highlights the potential clinical benefit of nintedanib plus docetaxel in patients who were unresponsive to prior immune checkpoint inhibitor therapy.

Also highly read was Nicolas Girard's (Institut du Thorax Curie-Montsouris, Paris, France) review discussing the optimization of outcomes and treatment sequences in EGFR mutation-positive non-small-cell lung cancer [6]. This review was an update on Girard's previous review published in Future Oncology in 2018, 'Optimizing outcomes in EGFR mutation-positive non-small-cell lung cancer: which tyrosine kinase inhibitor and when?' [7].

Special mention goes to the following articles which have achieved the highest Altmetric scores in the journal during 2019 as we continue our successful partnership with the platform:

- Our highest score was for the previously mentioned 'Sequential afatinib and osimertinib in patients with EGFR mutation-positive non-small-cell lung cancer: updated analysis of the observational GioTag study' - Altmetric score: 96 [3].

- We also received high scores for Toni Leigh Mortimer (Stellenbosch University, South Africa) and colleagues' review 'Cannabinoids: the lows and the highs of chemotherapy-induced nausea and vomiting' and Charles Dunton (Vermillion, TX, USA) and colleagues' original research article 'Ethnic disparity in clinical performance between multivariate index assay and CA125 in detection of ovarian malignancy' [8,9]. Altmetric scores: 68 and 53, respectively.

- Another high-scoring manuscript was a clinical trial protocol describing the rationale and design of AIPAC, a double-blind, randomized, multicenter Phase IIb study evaluating IMP321 plus paclitaxel as a first-line chemotherapy in hormone receptor-positive metastatic breast cancer patients [10]. Altmetric score: 44. 


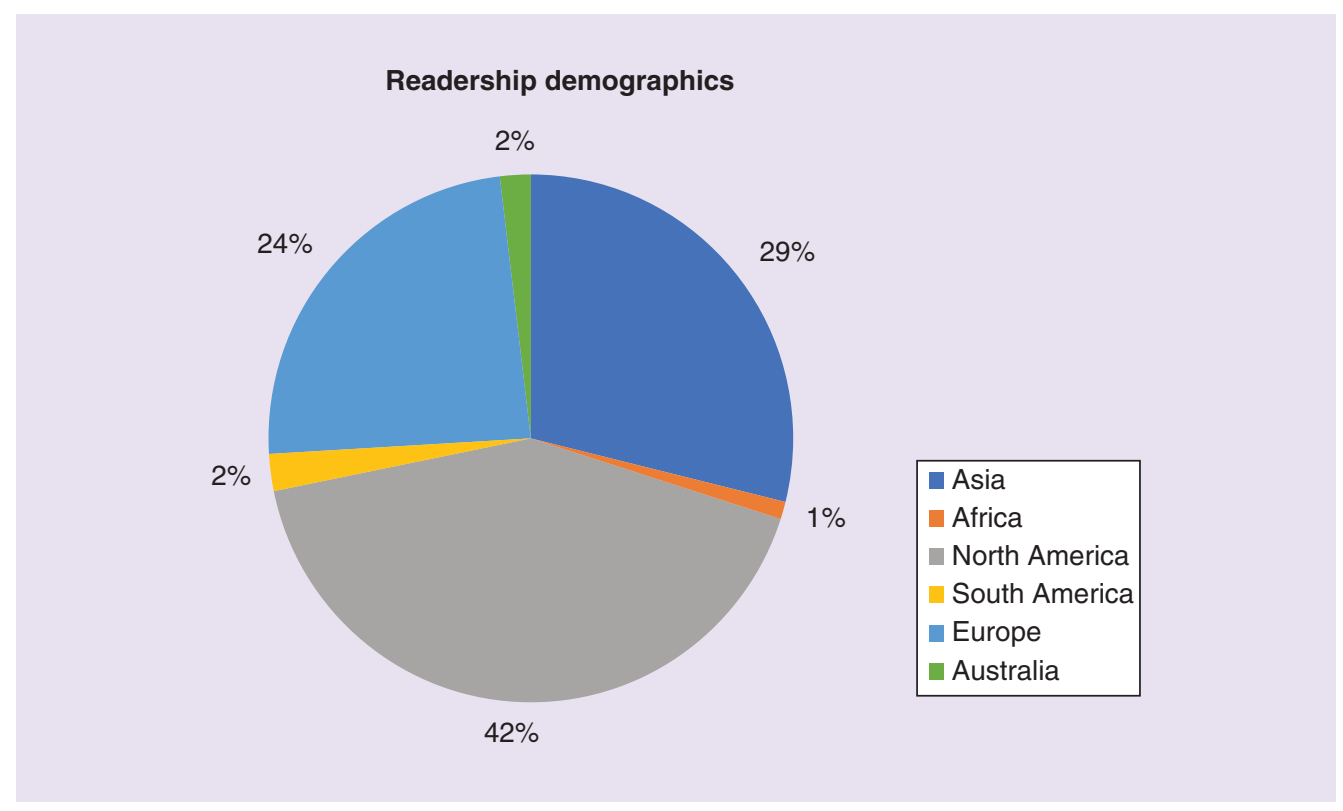

Figure 1. Proportion of readership demographics for Future Oncology in 2019.

- Finally, a more recently published open-access article that examines journal retractions in oncology, authored by Pan Pantziarka and Lydie Meheus (Anticancer Fund), has seen a quick and positive reception from the community [11]. Altmetric score: 41.

\section{Conference highlights}

The editorial team of Future Oncology attended a number of international and London-based conferences throughout 2019 and enjoyed connecting with authors and readers from across the globe. In attending these conferences, we facilitated poignant interviews with a number of noted researchers and members of our editorial board as well as gaining more of an awareness of ongoing research and critical issues in oncology. We hope to continue this over the year 2020.

OncologyCentral provided detailed coverage of all the conferences that we attended. Some noted conferences that we hope to attend again during 2020 are the following:

- American Association for Cancer Research (AACR) Annual Meeting 2019; Atlanta, GA, USA

- 2019 American Society of Clinical Oncology (ASCO) Annual Meeting; Chicago, IL, USA

- European Society for Medical Oncology (ESMO) Congress 2019; Barcelona, Spain

- 2019 National Cancer Research Institute (NCRI) Cancer Conference; Glasgow, UK

\section{Readership demographics}

It is great to see that, in 2019, our journal is being read throughout the world, with the highest number of readers being from North America (42\%), Asia (29\%) and Europe (24\%) (Figure 1). It is interesting to see that the number of readers from North America has increased from 35\% in 2018 to 42\% in 2019.

\section{Authorship demographics}

In 2019, we continue to receive high quality content from across the globe. Authors from Europe submitted the highest volume of content (42\%), followed by Asia and North America (21\%) (Figure 2). We have seen an increase in content from Asia, from $29 \%$ in 2018 to $34 \%$ in 2019.

\section{Social media}

Future Oncology continues to be active across all social media platforms, including our Future Science Oncology Group, hosted on LinkedIn, and our Twitter account, @fsgfon [12,13]. Our regular posts include journal highlights such as newly published content, most impactful articles and the latest oncology news. This year, we have thoroughly 


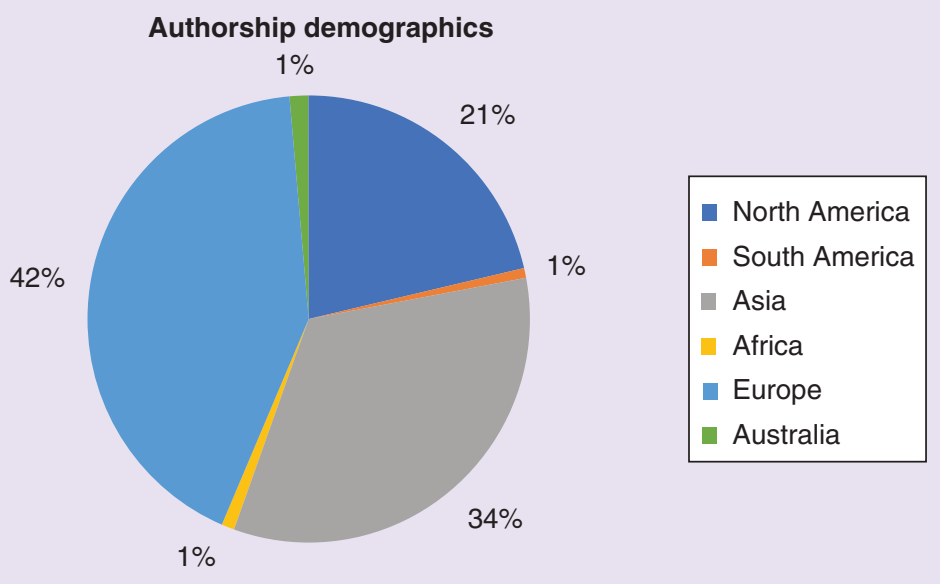

Figure 2. Proportion of authorship demographics for Future Oncology in 2019.

enjoyed engaging with oncology professionals across the field using a variety of materials, including infographics, graphical and video abstracts. We welcome readers to connect with us on various forms of social media going into 2020.

\section{Conclusion}

We appreciate all feedback from the oncology community regarding the direction of our content such as 'hot topics' in the field and trends that you feel should be covered in Future Oncology. We welcome unsolicited article proposals and would be delighted to hear from you. In particular, we encourage submissions on novel and translational work such as:

- Precision medicine

- Immunotherapy

- Real-world data

- Big data, AI and emerging technologies

- Integration of diagnostic and therapeutic approaches

- Optimizing treatment sequences

- Profiles of new anticancer drugs

- Biological processes involved in cancer and how new understanding will impact treatment

- Clinical implications and applications for new biomarkers

- Screening programs and methodology

- Impact of molecular genetics on prevention, screening, diagnosis and treatment

We greatly look forward to collaborating with you all over the next year and hope Future Oncology continues to fulfill its role in the medical community and grow and develop as a journal.

\section{Financial \& competing interests disclosure}

$R$ Jenkins and L Gautier are employees of Future Medicine Ltd. The authors have no other relevant affiliations or financial involvement with any organization or entity with a financial interest in or financial conflict with the subject matter or materials discussed in the manuscript apart from those disclosed.

No writing assistance was utilized in the production of this manuscript.

\section{References}

1. Caffo O. Treatment sequencing in oncology: balancing clinical trial and real-world evidence. Future Oncol. 15(25), 2887-2889 (2019).

2. Oncology Central. www.oncology-central.com/ 
3. Hochmair MJ, Morabito A, Hao D et al. Sequential afatinib and osimertinib in patients with EGFR mutation-positive non-small-cell lung cancer: updated analysis of the observational GioTag study. Future Oncol. 15(25), 2905-2914 (2019).

4. Hochmair MJ, Morabito A, Hao D et al. Sequential treatment with afatinib and osimertinib in patients with EGFR mutation-positive non-small-cell lung cancer: an observational study. Future Oncol. 14(27), 2861-2874 (2018).

5. Grohé C, Gleibier W, Haas S et al. Nintedanib plus docetaxel after progression on immune checkpoint inhibitor therapy: insights from VARGADO, a prospective study in patients with lung adenocarcinoma. Future Oncol. 15(23), 2699-2706 (2019).

6. Girard N. Optimizing outcomes and treatment sequences in EGFR mutation-positive non-small-cell lung cancer: recent updates. Future Oncol. 15(25), 2983), (2019).

7. Girard N. Optimizing outcomes in EGFR mutation-positive NSCLC: which tyrosine kinase inhibitor and when? Future Oncol. 14(11), 1117-1132 (2018).

8. Mortimer TL, Mabin T, Engelbert AM. Cannabinoids: the lows and the highs of chemotherapy-induced nausea and vomiting. Future Oncol. 15(9), 1035-1049 (2019).

9. Dunton C, Bullock RG, Fritsche H. Ethnic disparity in clinical performance between multivariate index assay and CA125 in detection of ovarian malignancy. Future Oncol. 15(26), 3047-3051 (2019).

10. Dirix L, Triebel F. AIPAC: a Phase IIb study of eftilagimod alpha (IMP321 or LAG-3Ig) added to weekly paclitaxel in patients with metastatic breast cancer. Future Oncol. 15(17), 1963-1973 (2019).

11. Pantiziarka P, Meheus L. Journal retractions in oncology: a bibliometric study. Future Oncol. 15(31), 3597-3608 (2019).

12. Future Science Group. www.linkedin.com/groups/8234713/

13. Future Oncology. https://twitter.com/fsgfon 